BMJ Open

Diabetes

Research

\& Care

\title{
Clinical characteristics and outcomes of patients with severe covid-19 with diabetes
}

\author{
Yongli Yan, Yan Yang (D) , Fen Wang, Huihui Ren, Shujun Zhang, Xiaoli Shi, \\ Xuefeng Yu (1) , Kun Dong
}

To cite: Yan $Y$, Yang $Y$, Wang $F$, et al. Clinical characteristics and outcomes of patients with severe covid-19 with diabetes. BMJ Open Diab Res Care 2020;8:e001343. doi:10.1136/ bmjdrc-2020-001343

Received 9 March 2020 Revised 2 April 2020 Accepted 6 April 2020

\section{SLinked}

- http://dx.doi.org/10.1136/ bmjdrc-2020-001450

\section{Check for updates}

(c) Author(s) (or their employer(s)) 2020. Re-use permitted under CC BY-NC. No commercial re-use. See rights and permissions. Published by BMJ.

Endocrinology, Tongji Hospital of Tongji Medical College of Huazhong University of Science and Technology, Wuhan, Hubei, China

Correspondence to

Mr Kun Dong;

kundong2019@hotmail.com

\section{ABSTRACT}

Objective This study explores the clinical characteristics of patients with diabetes with severe covid-19, and the association of diabetes with survival duration in patients with severe covid-19.

Research design and methods In this single-center, retrospective, observational study, the clinical and laboratory characteristics of 193 patients with severe covid-19 were collected. 48 patients with severe covid-19 had diabetes, and 145 patients (ie, the controls) did not have diabetes. A severe case was defined as including at least one of the following criteria: (1) Respiratory rate $>30$ / min. (2) Oxygen saturation $\leq 93 \%$. (3) $\mathrm{PaO}_{2} / \mathrm{FiO}_{2} \leq 300 \mathrm{~mm}$ $\mathrm{Hg}$. (4) Patients, either with shock or respiratory failure, requiring mechanical ventilation, or combined with other organ failure, requiring admission to intensive care unit (ICU).

Results Of 193 patients with severe covid-19, 48 (24.9\%) had diabetes. Compared with patients with severe covid-19 without diabetes, patients with diabetes were older, susceptible to receiving mechanical ventilation and admission to ICU, and had higher mortality. In addition, patients with severe covid-19 with diabetes had higher levels of leukocyte count, neutrophil count, high-sensitivity $C$ reaction protein, procalcitonin, ferritin, interleukin (IL) 2 receptor, IL-6, IL-8, tumor necrosis factor $\alpha$, D-dimer, fibrinogen, lactic dehydrogenase and $\mathrm{N}$-terminal probrain natriuretic peptide. Among patients with severe covid-19 with diabetes, more non-survivors were men (30 (76.9\%) vs $9(23.1 \%))$. Non-survivors had severe inflammatory response, and cardiac, hepatic, renal and coagulation impairment. Finally, the Kaplan-Meier survival curve showed a trend towards poorer survival in patients with severe covid-19 with diabetes than patients without diabetes. The HR was 1.53 (95\% Cl 1.02 to $2.30 ; p=0.041)$ after adjustment for age, sex, hypertension, cardiovascular disease and cerebrovascular disease by Cox regression. The median survival durations from hospital admission in patients with severe covid-19 with and without diabetes were 10 days and 18 days, respectively.

Conclusion The mortality rate in patients with severe covid-19 with diabetes is considerable. Diabetes may lead to an increase in the risk of death.

\section{INTRODUCTION}

The prevalence of covid-19 has dramatically spread worldwide, ${ }^{1-4}$ and a large number of patients is suffering from this fulminating

\section{Significance of this study}

What is already known about this subject?

- High morbidity has been observed in patients with severe covid- 19 with diabetes.

- Diabetes is considered a risk factor for complications in respiratory illness due to virus infection.

- The clinical course and outcomes of patients with severe covid-19 with diabetes remains unclear.

What are the new findings?

- Patients with severe covid-19 with diabetes exhibit severe inflammation response.

- Patients with severe covid-19 with diabetes were older, more likely to receive mechanical ventilation and admission to intensive care unit, and had higher mortality.

- The survival duration in patients with severe covid-19 with diabetes is obviously shorter than in those without diabetes.

How might these results change the focus of research or clinical practice?

- More attention should be paid to patients with severe covid-19 with diabetes, since those patients have high mortality.

infectious disease.${ }^{56}$ By the end of February 19, 2020, 74283 patients have been confirmed with covid-19 in the mainland of China, and the mortality rate is around $2.7 \% .^{7}$ Age and comorbidities are considered to be the main risk factors for increased risk of death in patients with covid-19. ${ }^{78}$

Recently, several studies have suggested that the prevalence of diabetes in patients with mild covid-19 may range from $5.7 \%$ to $5.9 \%,{ }^{89}$ while the prevalence of type 2 diabetes mellitus in patients with severe covid-19 has seen a sharp rise from $22.2 \%$ to $26.9 \% .^{89}$ These epidemiological evidences indicate a critical role of diabetes in patients with severe covid-19. Diabetes and hyperglycemia are reported to exacerbate inflammation by increasing the release of tumor necrosis factor $\alpha(\mathrm{TNF} \alpha)$ and interleukin (IL) $10{ }^{10-12}$ 
In addition, diabetes may lead to lung dysfunction, such as decreased forced expiratory volume and forced vital capacity. ${ }^{13}$ Therefore, diabetes could possibly be a risk factor for covid-19. Our study aims to investigate the clinical characteristics of patients with severe covid-19 with diabetes mellitus, and the association of diabetes with the outcome in patients with severe covid-19.

\section{RESEARCH DESIGN AND METHODS}

Study design and population

This is a single-center, retrospective, observational study. Tongji hospital is mainly responsible for the treatment of patients with severe covid-19 assigned by the government in Wuhan. All the participants were diagnosed with covid-19 according to WHO interim guidance. A total of 198 patients were treated at Tongji Hospital (Wuhan, China) from January 10, 2020 to February 24, 2020; 5 were excluded in accordance with the exclusion criteria. Patients were admitted under the following inclusion criteria: (1) Adults (over 18 years old). (2) Laboratory confirmation of covid-19 by real-time PCR. (3) Chest CT findings meeting the standard for diagnosis of covid-19. Patients were admitted under the following exclusion criteria: (1) Missing data on clinical characteristics. (2) Missing data on laboratory characteristics. (3) Secondary diabetes. (4) Type 1 diabetes. Finally, a total of 193 patients who had finished the completed medical records and follow-up were included. All the patients were community dwelling. All the procedures complied with the provisions of the Declaration of Helsinki. All participants provided oral informed consent.

\section{Data collection}

We reviewed the clinical records and laboratory data for all the patients. Two study investigators checked the data collected independently. We collected information on age, sex, chronic medical history (diabetes, hypertension, cardiovascular disease, cerebrovascular disease, chronic kidney disease, chronic pulmonary disease, chronic liver disease, treatment for diabetes and other comorbidities), clinical symptoms (fever, cough, dyspnea, pectoralgia, diarrhea, nausea, vomiting, anorexia, headache, fatigue) and living status. And we also collected laboratory data, such as blood routine, liver and renal function, random blood glucose, glycated hemoglobin, lipid, cardiac troponin I, high-sensitivity $\mathrm{C}$ reactive protein (hsCRP), ferritin, coagulation function, IL-2 receptor, IL-6, IL-8, IL-10 and TNF $\alpha$.

\section{Definitions}

Diabetes was defined as self-reported medical history of diabetes, and the use of antidiabetic drugs; otherwise, newly diagnosed diabetes was based on fasting plasma glucose, random plasma glucose and classic signs of hyperglycemia during hospital stay. (Considering critical condition in patients with severe covid-19, oral glucose tolerance test was not used for diagnosis of diabetes since hyperglycemia may lead to worsening of patient's illness.)
Diagnostic codes were mainly used to identify covid-19 patients with diabetes on admission to hospital. Severity of the disease was staged according to the guidelines for diagnosis and treatment of covid-19 (trial seventh edition) published by the National Health Commission of China on March 4, 2020. Severe cases were defined as including one of the following criteria: (1) Respiratory rate $>30 /$ min. (2) Oxygen saturation $\leq 93 \%$. 3. $\mathrm{PaO}_{2} /$ $\mathrm{FiO}_{2} \leq 300 \mathrm{~mm} \mathrm{Hg}$. (4) Patients developing either shock or respiratory failure requiring mechanical ventilation, or combined with other organ failure, requiring admission to intensive care unit (ICU). Moderate cases were defined as follows: (1) Patients with fever and respiratory symptoms. (2) Patients with obvious chest CT findings for covid-19 (such as ground-glass opacities). Mild cases were defined as follows: (1) Patients with mild clinical manifestation. (2) Patients without obvious chest CT findings for covid-19.

\section{Statistical analysis}

Data were analyzed using SPSS (V.22.0). A value of $p<0.05$ was considered statistically significant. Distribution of the continuous variables was carried out by the KolmogorovSmirnov test. Independent sample t-test was applied to analyze normally distributed data, and Mann-Whitney test was applied to analyze non-normally distributed data. The $\chi^{2}$ test was applied to examine categorical data. Kaplan-Meier survival curves were used to compare the 30-day survival rate for patients with severe covid-19 with and without diabetes by the log-rank test.

\section{RESULTS}

Our study included 193 hospitalized patients with severe covid-19. The median age was 64 (IQR 49-73) years, and $114(59.1 \%)$ were men. Among them, 76 (39.4\%) patients reported a history of exposure to patients with confirmed or highly suspected covid-19 infection, and 92 (47.7\%) patients were admitted to ICU. During hospitalization, $110(57.0 \%)$ patients received non-invasive or invasive mechanical ventilation treatment and 108 $(56.0 \%)$ critically ill patients died. The median length of hospital stay was 13 (IQR 7-16) days (table 1).

The most common symptoms were fever (89.6\%), cough $(69.9 \%)$, dyspnea $(59.6 \%)$ and fatigue $(52.3 \%)$ at the onset of illness. Some patients also presented with anorexia (35.2\%) and diarrhea (26.4\%). Other symptoms included headache, pectoralgia, nausea and vomiting. Ninety-four $(48.7 \%)$ patients had comorbidities, including hypertension $(37.8 \%)$, cardiovascular disease $(16.1 \%)$, cerebrovascular disease $(4.1 \%)$, chronic pulmonary disease $(7.3 \%)$, chronic kidney disease $(2.1 \%)$ and chronic liver disease $(0.5 \%)$ (table 1 ).

Of all patients, $48(24.9 \%)$ had diabetes and 145 $(75.1 \%)$ had no diabetes. Compared with patients without diabetes, patients with diabetes were older (median age, 70 (IQR 62-77) years vs 60 (IQR 43-71) years) and were more likely to have hypertension (24 (50.0\%) patients 
Table 1 The characteristics of patients with severe covid-19 with or without diabetes

\begin{tabular}{|c|c|c|c|c|}
\hline & Total $(n=193)$ & Diabetes $(n=48)$ & Non-diabetes $(n=145)$ & \multirow[b]{2}{*}{$P$ value* } \\
\hline & Number (\%) & Number (\%) & Number (\%) & \\
\hline Age, median (IQR), years & 64 (49 to 73$)$ & 70 (62 to 77$)$ & 60 (43 to 71$)$ & $<0.001$ \\
\hline \multicolumn{5}{|l|}{ Sex } \\
\hline Male & $114(59.1)$ & $33(68.8)$ & $81(55.9)$ & 0.115 \\
\hline Female & $79(40.9)$ & $15(31.3)$ & $64(44.1)$ & \\
\hline \multicolumn{5}{|l|}{ Symptoms } \\
\hline Fever & $173(89.6)$ & $43(89.6)$ & $130(89.7)$ & 0.989 \\
\hline Cough & $135(69.9)$ & $37(77.1)$ & $98(67.6)$ & 0.214 \\
\hline Dyspnea & $115(59.6)$ & $33(68.8)$ & $82(56.6)$ & 0.136 \\
\hline Pectoralgia & $10(5.2)$ & $1(2.1)$ & $9(6.2)$ & 0.458 \\
\hline Diarrhea & $51(26.4)$ & $10(20.8)$ & $41(28.3)$ & 0.311 \\
\hline Nausea & $14(7.3)$ & $2(4.2)$ & $12(8.3)$ & 0.528 \\
\hline Vomiting & $5(2.6)$ & $2(4.2)$ & $3(2.1)$ & 0.788 \\
\hline Anorexia & $68(35.2)$ & $21(43.8)$ & $47(32.4)$ & 0.154 \\
\hline Headache & $21(10.9)$ & $5(10.4)$ & $16(11.0)$ & 0.905 \\
\hline Fatigue & $101(52.3)$ & 28 (58.3) & $73(50.3)$ & 0.337 \\
\hline Comorbidities & $94(48.7)$ & $29(60.4)$ & $65(44.8)$ & 0.061 \\
\hline Hypertension & $73(37.8)$ & $24(50.0)$ & $49(33.8)$ & 0.045 \\
\hline Cardiovascular disease & $31(16.1)$ & $13(27.1)$ & $18(12.4)$ & 0.016 \\
\hline Cerebrovascular disease & $8(4.1)$ & $5(10.4)$ & $3(2.1)$ & 0.036 \\
\hline Chronic kidney disease & $4(2.1)$ & $0(0.0)$ & $4(2.8)$ & 0.574 \\
\hline Chronic pulmonary disease & $14(7.3)$ & $4(8.3)$ & $10(6.9)$ & 0.739 \\
\hline Chronic liver disease & $1(0.5)$ & $0(0.0)$ & $1(0.7)$ & 1.000 \\
\hline Exposure to disease & $76(39.4)$ & $17(35.4)$ & $59(40.7)$ & 0.517 \\
\hline ICU patients & $92(47.7)$ & $32(66.7)$ & $60(41.4)$ & 0.002 \\
\hline Mechanical ventilation treatment $\dagger$ & $110(57.0)$ & $39(81.3)$ & $71(49.0)$ & $<0.001$ \\
\hline Length of hospital stay, median (IQR), days & $13(7$ to 16$)$ & $10(6$ to 13$)$ & 13 (9 to 18$)$ & 0.001 \\
\hline Mortality & $108(56.0)$ & $39(81.3)$ & $69(47.6)$ & $<0.001$ \\
\hline
\end{tabular}

${ }^{*} P$ values indicate differences between diabetes and non-diabetes. A value of $p<0.05$ was considered statistically significant. †Non-invasive mechanical ventilation and invasive mechanical ventilation were included. Non-invasive mechanical ventilation included bilevel positive airway pressure ventilation or high-flow nasal cannula oxygen therapy.

ICU, intensive care unit.

vs $49(33.8 \%)$ patients), cardiovascular disease (13 (27.1\%) patients vs $18(12.4 \%)$ patients) and cerebrovascular disease (5 (10.4\%) patients vs $3(2.1 \%)$ patients). Neither the symptoms nor other comorbidities were significantly different between patients with diabetes and those without. Compared with patients without diabetes, more patients with diabetes were admitted to ICU (32 $(66.7 \%)$ patients vs $60(41.4 \%)$ patients) and received mechanical ventilation treatment $(39(81.3 \%)$ patients vs $71(49.0 \%)$ patients). Patients with diabetes also had a shorter duration of hospital stay (10 (IQR 6-13) days vs 13 (IQR 9-18) days) and higher mortality (81.3\% vs $47.6 \%$ ) than patients without diabetes (table 1 ).

As shown in table 2, numerous biochemical values were significantly different between patients with diabetes and those without. Obviously patients with diabetes had higher levels of random blood glucose $(11.31 \mathrm{mmol} / \mathrm{L}$ vs $6.56 \mathrm{mmol} / \mathrm{L})$ and glycated hemoglobin $(7.2 \%$ vs $5.8 \%)$. On admission, patients with diabetes had higher levels of leukocyte count $\left(7.99 \times 10^{9} / \mathrm{L}\right.$ vs $\left.5.55 \times 10^{9} / \mathrm{L}\right)$, neutrophil count $\left(7.25 \times 10^{9} / \mathrm{L}\right.$ vs $\left.3.94 \times 10^{9} / \mathrm{L}\right)$, hsCRP $(75.5 \mathrm{mg} / \mathrm{L}$ vs $43.3 \mathrm{mg} / \mathrm{L})$, procalcitonin $(0.16 \mathrm{ng} / \mathrm{mL}$ vs $0.09 \mathrm{ng} / \mathrm{mL})$, ferritin $(1373.0 \mu \mathrm{g} / \mathrm{L}$ vs $630.5 \mu \mathrm{g} / \mathrm{L})$, IL-2 receptor $(1098$ $\mathrm{U} / \mathrm{mL}$ vs $649 \mathrm{U} / \mathrm{mL})$, IL-6 $(47.08 \mathrm{pg} / \mathrm{mL}$ vs $21.31 \mathrm{pg} /$ $\mathrm{mL})$, IL-8 (26.0 pg/mL vs $16.4 \mathrm{pg} / \mathrm{mL})$, TNF $\alpha$ (11.3 pg/ $\mathrm{mL}$ vs $8.3 \mathrm{pg} / \mathrm{mL})$, D-dimer $(2.6 \mu \mathrm{g} / \mathrm{mL}$ fibrinogen equivalent units (FEU) vs $1.2 \mu \mathrm{g} / \mathrm{mL}$ FEU), lactic dehydrogenase $(465 \mathrm{U} / \mathrm{L}$ ws $330 \mathrm{U} / \mathrm{L})$ and N-terminal pro-brain natriuretic peptide (NT-proBNP) $(665 \mathrm{pg} / \mathrm{mL}$ vs $259 \mathrm{pg} /$ $\mathrm{mL}$ ). And most of these values in both groups were above the normal range, which indicated patients with diabetes had more severe inflammatory response and myocardial 
Table 2 The biochemical values in patients with severe covid-19 with or without diabetes on admission to hospital

\begin{tabular}{|c|c|c|c|c|}
\hline & & Diabetes $(n=48)$ & Non-diabetes $(n=145)$ & \\
\hline & Normal range & Median (IQR) & Median (IQR) & $P$ value* \\
\hline Random blood glucose, $\mathrm{mmol} / \mathrm{L}$ & & 11.31 (7.96 to 16.79$)$ & 6.56 (5.59 to 8.08$)$ & $<0.001$ \\
\hline Glycated hemoglobin, \% & $4.0-6.0$ & $7.2(6.7$ to 8.3$)$ & $5.8(5.5$ to 6.1$)$ & $<0.001$ \\
\hline Leukocyte count, $\times 10^{9} / \mathrm{L}$ & $3.50-9.50$ & 7.99 (5.90 to 13.04$)$ & 5.55 (4.20 to 8.43$)$ & 0.001 \\
\hline Neutrophil count, $\times 10^{9} / \mathrm{L}$ & $1.80-6.30$ & $7.25(4.33$ to 11.81$)$ & 3.94 (2.54 to 7.71$)$ & $<0.001$ \\
\hline Lymphocyte count, $\times 10^{9} / \mathrm{L}$ & $1.10-3.20$ & 0.54 (0.42 to 0.93$)$ & 0.81 (0.56 to 1.24$)$ & 0.001 \\
\hline Hemoglobin, g/L & $115.0-150.0$ & 128.5 (115.0 to 140.0$)$ & $130.0(118.0$ to 142.0$)$ & 0.775 \\
\hline Platelet count, $\times 10^{9} / \mathrm{L}$ & $125.0-350.0$ & 161.0 (126.5 to 232.5$)$ & 173.0 (130.0 to 230.0$)$ & 0.503 \\
\hline Prothrombin time, s & $11.5-14.5$ & 14.4 (13.6 to 17.0$)$ & $14.3(13.2$ to 15.5$)$ & 0.094 \\
\hline Thrombin time, s & $14.0-19.0$ & 17.1 (15.8 to 19.8$)$ & 16.4 (15.6 to 17.7$)$ & 0.014 \\
\hline APTT, s & $29.0-42.0$ & 38.4 (35.7 to 45.5$)$ & 40.2 (36.8 to 44.1$)$ & 0.483 \\
\hline Fibrinogen, $g / L$ & $2.00-4.00$ & 4.85 (3.32 to 6.70$)$ & 4.31 (3.34 to 5.35$)$ & 0.085 \\
\hline D-dimer, $\mu \mathrm{g} / \mathrm{mL}$ FEU & $<0.5$ & $2.6(1.0$ to 21.0$)$ & $1.2(0.4$ to 10.7$)$ & 0.012 \\
\hline Alanine aminotransferase, $\mathrm{U} / \mathrm{L}$ & $\leq 33.0$ & 22.5 (16.3 to 40.0 ) & 22.0 (15.0 to 38.3 ) & 0.454 \\
\hline Aspartate aminotransferase, $\mathrm{U} / \mathrm{L}$ & $\leq 32.0$ & 34.0 (21.3 to 58.3$)$ & 31.0 (22.0 to 47.0$)$ & 0.472 \\
\hline Albumin, mean $\pm S D, g / L$ & $35.0-52.0$ & $32.2 \pm 5.2$ & $34.9 \pm 6.4$ & 0.009 \\
\hline Total bilirubin, $\mu \mathrm{mol} / \mathrm{L}$ & $\leq 21.0$ & $11.3(7.5$ to 20.6$)$ & $8.7(6.5$ to 13.4$)$ & 0.008 \\
\hline Creatine kinase, $\mathrm{U} / \mathrm{L}$ & $\leq 170.0$ & 132.0 (70.0 to 290.0$)$ & 106.5 (63.8 to 233.3) & 0.329 \\
\hline Lactic dehydrogenase, U/L & $135-214$ & 465 (306 to 645$)$ & 330 (231 to 535$)$ & 0.011 \\
\hline Cholesterol, $\mathrm{mmol} / \mathrm{L}$ & $<5.18$ & 3.41 (2.96 to 4.26$)$ & 3.45 (2.98 to 4.06$)$ & 0.701 \\
\hline Triglyceride, $\mathrm{mmol} / \mathrm{L}$ & $<1.70$ & 1.79 (1.24 to 2.36$)$ & $1.34(0.89$ to 1.79$)$ & 0.003 \\
\hline Urea nitrogen, $\mathrm{mmol} / \mathrm{L}$ & $3.1-8.8$ & 8.0 (5.1 to 11.0$)$ & 5.3 (3.6 to 9.0$)$ & 0.003 \\
\hline Creatinine, $\mu \mathrm{mol} / \mathrm{L}$ & $45.0-84.0$ & 83.5 (65.8 to 102.3$)$ & 78.0 (58.0 to 100.0$)$ & 0.264 \\
\hline Uric acid, $\mu \mathrm{mol} / \mathrm{L}$ & $202.3-416.5$ & 273.2 (183.3 to 356.8$)$ & 276.0 (205.0 to 352.9$)$ & 0.927 \\
\hline hsCRP, mg/L & $<1.0$ & 75.5 (49.9 to 150.5$)$ & $43.3(11.0$ to 116.5$)$ & 0.004 \\
\hline $\mathrm{ESR}, \mathrm{mm} / \mathrm{H}$ & $0.0-20.0$ & 38.0 (15.0 to 65.8$)$ & 27.0 (14.5 to 43.5$)$ & 0.140 \\
\hline Procalcitonin, $\mathrm{ng} / \mathrm{mL}$ & $0.02-0.05$ & 0.16 (0.09 to 0.78$)$ & 0.09 (0.04 to 0.20$)$ & 0.001 \\
\hline Ferritin, $\mu \mathrm{g} / \mathrm{L}$ & $15.0-150.0$ & 1373.0 (738.2 to 2457.0$)$ & 630.5 (266.1 to 1659.0$)$ & 0.001 \\
\hline IL-2 receptor, U/mL & $223-710$ & 1098 (626 to 1538) & 649 (407 to 1193$)$ & 0.002 \\
\hline IL-6, pg/mL & $<7.00$ & 47.08 (19.04 to 126.80$)$ & 21.31 (7.67 to 64.06$)$ & 0.006 \\
\hline IL-8, pg/mL & $<62.0$ & 26.0 (14.9 to 54.4$)$ & 16.4 (9.9 to 41.0$)$ & 0.032 \\
\hline $\mathrm{IL}-10, \mathrm{pg} / \mathrm{mL}$ & $<9.10$ & 10.20 (5.85 to 17.43$)$ & 9.00 (5.00 to 13.65$)$ & 0.128 \\
\hline $\mathrm{TNF} \alpha, \mathrm{pg} / \mathrm{mL}$ & $<8.1$ & $11.3(7.4$ to 18.3$)$ & $8.3(6.9$ to 12.1$)$ & 0.023 \\
\hline NT-proBNP, pg/mL & $<285$ & 665 (170 to 2053) & 259 (46 to 901$)$ & 0.007 \\
\hline Cardiac troponin I, pg/mL & $\leq 15.60$ & 23.05 (8.70 to 208.60$)$ & 10.20 (3.60 to 38.40$)$ & 0.059 \\
\hline
\end{tabular}

${ }^{*} P$ values indicate differences between diabetes and non-diabetes. A value of $p<0.05$ was considered statistically significant.

APTT, activated partial thromboplastin time; ESR, erythrocyte sedimentation rate; FEU, fibrinogen equivalent units; hsCRP, high-sensitivity C-reaction protein; IL, interleukin; NT-proBNP, N-terminal pro-brain natriuretic peptide; TNF $\alpha$, tumor necrosis factor $\alpha$.

damage. The level of cardiac troponin I had no statistically significant difference between the two groups, but showed a higher trend in patients with diabetes. The levels of lymphocyte count $\left(0.54 \times 10^{9} / \mathrm{L}\right.$ vs $\left.0.81 \times 10^{9} / \mathrm{L}\right)$ and albumin $(32.2 \mathrm{~g} / \mathrm{L}$ vs $34.9 \mathrm{~g} / \mathrm{L})$ were below the normal range in both groups and patients with diabetes had lower values than patients without diabetes. In addition, most patients had normal liver and kidney function, although patients with diabetes had higher levels of total bilirubin $(11.3 \mu \mathrm{mol} / \mathrm{L}$ vs $8.7 \mu \mathrm{mol} / \mathrm{L})$, triglyceride $(1.79$ $\mu \mathrm{mol} / \mathrm{L}$ vs $1.34 \mathrm{mmol} / \mathrm{L})$ and urea nitrogen $(8.0 \mu \mathrm{mol} / \mathrm{L}$ vs $5.3 \mathrm{mmol} / \mathrm{L}$ ) compared with patients without diabetes.

Eighty-five $(44.0 \%)$ of all patients with severe covid-19 survived. Compared with survivors, non-survivors were significantly older (median age, 70 (IQR 62-78) years vs 46 (IQR 37-64) years) and there were more men who died (76 $(70.4 \%)$ patients vs $38(44.7 \%)$ patients). Non-survivors were more likely to have chronic diseases, 
Table 3 The baseline characteristics of survivors and non-survivors infected with severe covid-19

\begin{tabular}{|c|c|c|c|c|}
\hline & Total $(n=193)$ & Survivors $(n=85)$ & Non-survivors $(n=108)$ & \\
\hline & Number (\%) & Number (\%) & Number (\%) & $P$ value $^{*}$ \\
\hline Age, median (IQR), years & 64 (49 to 73 ) & 46 (37 to 64$)$ & 70 (62 to 78$)$ & $<0.001$ \\
\hline \multicolumn{5}{|l|}{ Sex } \\
\hline Male & $114(59.1)$ & $38(44.7)$ & $76(70.4)$ & $<0.001$ \\
\hline Female & 79 (40.9) & 47 (55.3) & $32(29.6)$ & \\
\hline Diabetes mellitus & $48(24.9)$ & $9(10.6)$ & $39(36.1)$ & $<0.001$ \\
\hline Hypertension & $73(37.8)$ & $16(18.8)$ & $57(52.8)$ & $<0.001$ \\
\hline Cardiovascular disease & $31(16.1)$ & $4(4.7)$ & $27(25.0)$ & $<0.001$ \\
\hline Cerebrovascular disease & $8(4.1)$ & $0(0.0)$ & $8(7.4)$ & 0.010 \\
\hline Chronic kidney disease & $4(2.1)$ & $1(1.2)$ & $3(2.8)$ & 0.790 \\
\hline Chronic pulmonary disease & $14(7.3)$ & $3(3.5)$ & $11(10.2)$ & 0.136 \\
\hline Chronic liver disease & $1(0.5)$ & $0(0.0)$ & $1(0.9)$ & 1.000 \\
\hline ICU patients & $92(47.7)$ & $1(1.2)$ & $91(84.3)$ & $<0.001$ \\
\hline Glucocorticoid treatment & $136(70.5)$ & $41(48.2)$ & 95 (88.0) & $<0.001$ \\
\hline Mechanical ventilation treatment $†$ & $110(57.0)$ & $5(5.9)$ & $105(97.2)$ & $<0.001$ \\
\hline Length of hospital stay, median (IQR), days & $13(7$ to 16$)$ & 15 (13 to 23$)$ & 9 (5 to 13$)$ & $<0.001$ \\
\hline
\end{tabular}

${ }^{*} P$ values indicate differences between survivors and non-survivors. A value of $p<0.05$ was considered statistically significant. †Non-invasive mechanical ventilation and invasive mechanical ventilation were included. Non-invasive mechanical ventilation included bilevel positive airway pressure ventilation or high-flow nasal cannula oxygen therapy.

ICU, intensive care unit.

including diabetes $(39(36.1 \%)$ patients vs $9(10.6 \%)$ patients), hypertension (57 $(52.8 \%)$ patients vs 16 $(18.8 \%)$ patients), cardiovascular disease $(27(25.0 \%)$ patients vs $4(4.7 \%)$ patients), cerebrovascular disease (8 $(7.4 \%)$ patients vs $0(0.0 \%)$ patients). Most non-survivors were admitted to ICU (84.3\%) and non-survivors were more likely to receive glucocorticoid treatment (95 $(88.0 \%)$ patients vs 41 (48.2\%) patients) and mechanical ventilation treatment $(105(97.2 \%)$ patients vs 5 $(5.9 \%)$ patients). Non-survivors had significantly shorter duration of hospital stay (9 (IQR 5-13) days vs 15 (IQR 13-23) days) than survivors (table 3 ).

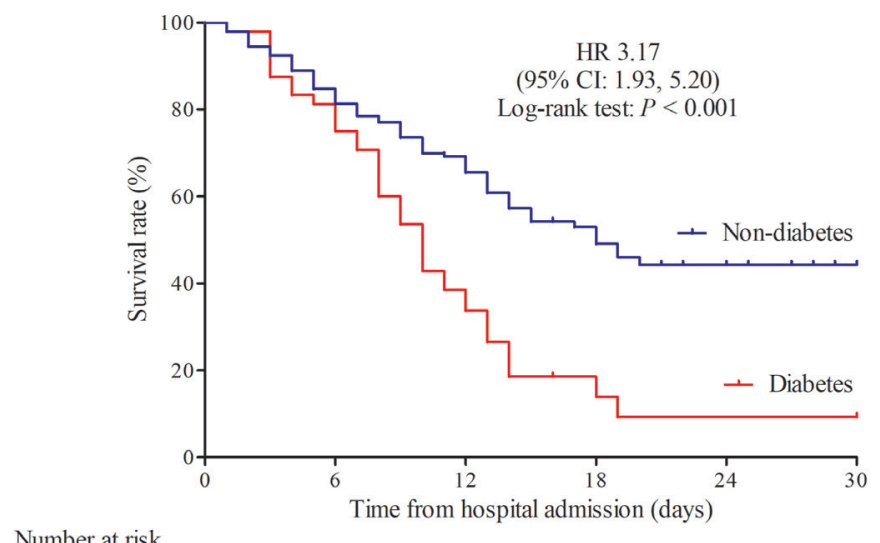

Number at risk

Diabetes 48

39

Non-diabetes 145

39
122

16

4

1

20

Figure 1 Kaplan-Meier survival curve for patients with

severe covid-19 with and without diabetes.
Among patients with severe covid-19 with diabetes, 39 $(81.2 \%)$ patients died. The Kaplan-Meier survival curve also showed a trend toward poorer survival in patients with diabetes compared with patients without diabetes, and the HR was 3.17 (95\% CI 1.93 to 5.20) (figure 1). The median survival duration from hospital admission was 10 days in patients with diabetes and was 18 days in patients without diabetes. After adjustment for age and sex by Cox regression, the HR was 1.66 (95\% CI 1.11 to 2.47; $\mathrm{p}=0.013$ ). After further adjustment for hypertension, cardiovascular disease and cerebrovascular disease, patients with diabetes still had a lower survival rate than patients without diabetes (HR 1.53 (95\% CI 1.02 to 2.30); $\mathrm{p}=0.041$ ). In addition, the median survival duration from symptom appearance was 21 days in patients with diabetes and 28 days in patients without diabetes. The Kaplan-Meier survival curve also showed a lower survival rate in patients with diabetes compared with patients without diabetes, and the HR was 2.60 (95\% CI 1.62 to 4.18; $\mathrm{p}<0.001)$.

Of 48 patients with severe covid-19 with diabetes, men were more likely to die. Compared with survivors with diabetes, non-survivors had longer diabetes duration, and more non-survivors reported cough and dyspnea. Age, medicine control for diabetes, glycated hemoglobin, other symptoms and comorbidities between survivors and non-survivors with diabetes showed no significant differences. More non-survivors were admitted to ICU, received mechanical ventilation treatment and glucocorticoid treatment, but had significantly shorter duration 
Table 4 The baseline characteristics of survivors and non-survivors in patients with severe covid-19 with diabetes

\begin{tabular}{|c|c|c|c|c|}
\hline & \multirow{2}{*}{$\begin{array}{l}\text { Total }(n=48) \\
\text { Number }(\%)\end{array}$} & \multirow{2}{*}{$\begin{array}{l}\text { Survivors }(\mathbf{n}=9) \\
\text { Number }(\%)\end{array}$} & \multirow{2}{*}{$\begin{array}{l}\text { Non-survivors }(\mathrm{n}=39) \\
\text { Number }(\%) \\
\end{array}$} & \multirow[b]{2}{*}{$P$ value* } \\
\hline & & & & \\
\hline Age, mean $\pm S D$, years & $69.4 \pm 9.9$ & $64.7 \pm 7.3$ & $70.5 \pm 10.1$ & 0.112 \\
\hline \multicolumn{5}{|l|}{ Sex } \\
\hline Male & $33(68.8)$ & $3(33.3)$ & $30(76.9)$ & 0.032 \\
\hline Female & $15(31.3)$ & $6(66.7)$ & $9(23.1)$ & \\
\hline Diabetes duration, median (IQR), years & $2(1$ to 5$)$ & $0.5(0.5$ to 2.5$)$ & $2(1$ to 5$)$ & 0.021 \\
\hline \multicolumn{5}{|l|}{ Medicine control for diabetes $\dagger$} \\
\hline No medication & $20 / 34(58.8)$ & $6 / 9(66.7)$ & $14 / 25(56.0)$ & 0.266 \\
\hline Oral medication & 10/34 (29.4) & 3/9 (33.3) & $7 / 25(28.0)$ & \\
\hline Insulin & $4 / 34(11.8)$ & $0 / 9(0.0)$ & $4 / 25(16.0)$ & \\
\hline \multicolumn{5}{|l|}{ Glycated hemoglobin, \% } \\
\hline$<7.0$ & $17(35.4)$ & $4(44.4)$ & $13(33.3)$ & 0.852 \\
\hline$\geq 7.0,<8.0$ & $16(33.3)$ & $2(22.2)$ & $14(35.9)$ & \\
\hline$\geq 8.0,<9.0$ & $11(22.9)$ & $2(22.2)$ & $9(23.1)$ & \\
\hline$\geq 9.0$ & $4(8.3)$ & $1(11.1)$ & $3(7.7)$ & \\
\hline \multicolumn{5}{|l|}{ Symptoms } \\
\hline Fever & $43(89.6)$ & $7(77.8)$ & $36(92.3)$ & 0.496 \\
\hline Cough & $37(77.1)$ & $3(33.3)$ & $34(87.2)$ & 0.002 \\
\hline Dyspnea & $33(68.8)$ & $3(33.3)$ & 30 (76.9) & 0.032 \\
\hline Diarrhea & $10(20.8)$ & $4(44.4)$ & $6(15.4)$ & 0.139 \\
\hline Nausea & $2(4.2)$ & $0(0.0)$ & $2(5.1)$ & 1.000 \\
\hline Anorexia & $21(43.8)$ & $2(22.2)$ & $19(48.7)$ & 0.284 \\
\hline Headache & $5(10.4)$ & $0(0.0)$ & $5(12.8)$ & 0.568 \\
\hline Fatigue & $28(58.3)$ & $4(44.4)$ & $24(61.5)$ & 0.574 \\
\hline \multicolumn{5}{|l|}{ Comorbidities } \\
\hline Hypertension & $24(50.0)$ & $3(33.3)$ & $21(53.8)$ & 0.460 \\
\hline Cardiovascular disease & $13(27.1)$ & $2(22.2)$ & $11(28.2)$ & 1.000 \\
\hline Cerebrovascular disease & $5(10.4)$ & $0(0.0)$ & $5(12.8)$ & 0.568 \\
\hline Chronic pulmonary disease & $4(8.3)$ & $0(0.0)$ & $4(10.3)$ & 1.000 \\
\hline Exposure to disease & $17(35.4)$ & $6(66.7)$ & $11(28.2)$ & 0.074 \\
\hline ICU patients & $32(66.7)$ & $0(0.0)$ & $32(82.1)$ & $<0.001$ \\
\hline Glucocorticoid treatment & $39(81.3)$ & $4(44.4)$ & $35(89.7)$ & 0.008 \\
\hline Mechanical ventilation treatmentł & $39(81.3)$ & $1(11.1)$ & 38 (97.4) & $<0.001$ \\
\hline Length of hospital stay, median (IQR), days & $10(6$ to 13$)$ & $14(11$ to 18$)$ & $9(6$ to 12$)$ & 0.004 \\
\hline
\end{tabular}

${ }^{*} P$ values indicate differences between survivors and non-survivors. A value of $p<0.05$ was considered statistically significant. †Data were expressed as $\mathrm{n} / \mathrm{N}(\%)$, where $\mathrm{N}$ indicated available total cases.

$\ddagger$ Non-invasive and invasive mechanical ventilation were included. Non-invasive mechanical ventilation included bilevel positive airway pressure ventilation or high-flow nasal cannula oxygen therapy.

ICU, intensive care unit.

of hospital stay, which reflected the rapid progress of disease in non-survivors (table 4).

Compared with survivors with diabetes, non-survivors had higher levels of leukocyte count, neutrophil count, hsCRP, procalcitonin, ferritin, IL-2 receptor, IL-6, TNF $\alpha$, and lower levels of lymphocyte count, which indicated non-survivors with diabetes had more severe inflammatory response. Non-survivors with diabetes also had a lower level of albumin, and higher levels of total bilirubin, aspartate aminotransferase, creatine kinase, lactic dehydrogenase, urea nitrogen, creatine, cardiac troponin I, NT-proBNP, prothrombin time, D-dimer than survivors, reflecting severe cardiac, hepatic, renal and coagulation impairment (table 5).

\section{DISCUSSION}

The purpose of this present retrospective study was to figure out the clinical characteristics of patients with severe covid-19 with diabetes, and evaluate the role of 
Table 5 The biochemical values of survivors and non-survivors in patients with severe covid-19 with diabetes on admission to hospital

\begin{tabular}{|c|c|c|c|c|}
\hline & \multirow[b]{2}{*}{ Normal range } & \multirow{2}{*}{$\begin{array}{l}\text { Survivors (n=9) } \\
\text { Median (IQR) }\end{array}$} & \multirow{2}{*}{$\begin{array}{l}\text { Non-survivors ( } \mathrm{n}=39 \text { ) } \\
\text { Median (IQR) }\end{array}$} & \multirow[b]{2}{*}{$P$ value* } \\
\hline & & & & \\
\hline Random blood glucose, $\mathrm{mmol} / \mathrm{L}$ & & 9.02 (6.39 to 13.73$)$ & 12.38 (8.39 to 17.35$)$ & 0.096 \\
\hline Glycated hemoglobin, $\operatorname{mean} \pm S D, \%$ & $4.0-6.0$ & $7.6 \pm 1.3$ & $7.4 \pm 1.0$ & 0.639 \\
\hline Leukocyte count, $\times 10^{9} / \mathrm{L}$ & $3.50-9.50$ & 4.93 (3.50 to 7.58$)$ & 9.09 (6.20 to 13.34$)$ & 0.004 \\
\hline Neutrophil count, $\times 10^{9} / \mathrm{L}$ & $1.80-6.30$ & 3.23 (2.26 to 5.38$)$ & 8.04 (5.36 to 12.49$)$ & 0.001 \\
\hline Lymphocyte count, $\times 10^{9} / \mathrm{L}$ & $1.10-3.20$ & 0.94 (0.54 to 1.84$)$ & $0.50(0.34$ to 0.76$)$ & 0.024 \\
\hline Hemoglobin, g/L & $115.0-150.0$ & $125.0(112.0$ to 141.5$)$ & 131 (115 to 140$)$ & 0.682 \\
\hline Platelet count, $\times 10^{9} / \mathrm{L}$ & $125.0-350.0$ & $161.0(159.5$ to 286.5$)$ & 160.0 (113.0 to 228.0$)$ & 0.219 \\
\hline Prothrombin time, s & $11.5-14.5$ & 13.6 (13.2 to 14.4$)$ & $15.2(13.8$ to 17.4$)$ & 0.007 \\
\hline Thrombin time, s & $14.0-19.0$ & 16.1 (15.7 to 17.0$)$ & 18.1 (15.8 to 20.0$)$ & 0.124 \\
\hline APTT, s & $29.0-42.0$ & 36.3 (33.9 to 42.7 ) & 39.0 (36.1 to 45.5$)$ & 0.188 \\
\hline Fibrinogen, mean $\pm S D, g / L$ & $2.00-4.00$ & $4.80 \pm 1.38$ & $5.08 \pm 2.50$ & 0.748 \\
\hline D-dimer, $\mu \mathrm{g} / \mathrm{mL}$ FEU & $<0.5$ & 0.41 (0.26 to 0.89$)$ & 4.95 (1.80 to 21.00$)$ & $<0.001$ \\
\hline Alanine aminotransferase, $\mathrm{U} / \mathrm{L}$ & $\leq 33.0$ & 20.0 (13.5 to 31.5$)$ & 23.0 (17.0 to 40.0$)$ & 0.369 \\
\hline Aspartate aminotransferase, U/L & $\leq 32.0$ & 26.0 (16.5 to 34.0$)$ & 41.0 (24.0 to 63.0$)$ & 0.023 \\
\hline Albumin, mean $\pm S D, g / L$ & $35.0-52.0$ & $37.2 \pm 2.6$ & $31.0 \pm 5.0$ & 0.001 \\
\hline Total bilirubin, $\mu \mathrm{mol} / \mathrm{L}$ & $\leq 21.0$ & $7.5(6.5$ to 11.1$)$ & 13.4 (9.3 to 22.2$)$ & 0.007 \\
\hline Creatine kinase, U/L & $\leq 170.0$ & 76.5 (46.5 to 107.3$)$ & 207.0 (92.0 to 331.0$)$ & 0.013 \\
\hline Lactic dehydrogenase, U/L & $135-214$ & 237 (185 to 296$)$ & 501 (359 to 748 ) & $<0.001$ \\
\hline Cholesterol, mean $\pm \mathrm{SD}, \mathrm{mmol} / \mathrm{L}$ & $<5.18$ & $3.75 \pm 0.69$ & $3.56 \pm 1.00$ & 0.599 \\
\hline Triglyceride, $\mathrm{mmol} / \mathrm{L}$ & $<1.70$ & 1.12 (1.00 to 2.04$)$ & 1.92 (1.52 to 2.59$)$ & 0.086 \\
\hline Urea nitrogen, $\mathrm{mmol} / \mathrm{L}$ & $3.1-8.8$ & 2.9 (2.7 to 4.6$)$ & 9.5 (6.2 to 12.7$)$ & $<0.001$ \\
\hline Creatinine, $\mu \mathrm{mol} / \mathrm{L}$ & $45.0-84.0$ & 65.0 (53.5 to 79.5$)$ & 88.0 (73.0 to 114.0$)$ & 0.014 \\
\hline Uric acid, $\mu \mathrm{mol} / \mathrm{L}$ & $202.3-416.5$ & $263.0(167.0$ to 318.4$)$ & 277.3 (184.0 to 374.0 ) & 0.376 \\
\hline hsCRP, mg/L & $<1.0$ & $13.0(1.0$ to 48.0$)$ & 97.2 (64.4 to 191.0$)$ & $<0.001$ \\
\hline $\mathrm{ESR}, \mathrm{mm} / \mathrm{H}$ & $0.0-20.0$ & $32.0(4.3$ to 50.5$)$ & 38.5 (15.8 to 77.5$)$ & 0.230 \\
\hline Procalcitonin, ng/mL & $0.02-0.05$ & 0.05 (0.03 to 0.08$)$ & 0.38 (0.13 to 1.18$)$ & $<0.001$ \\
\hline Ferritin, $\mu \mathrm{g} / \mathrm{L}$ & $15.0-150.0$ & 432.5 (245.8 to 809.1$)$ & 1612.0 (1125.0 to 2733.0$)$ & $<0.001$ \\
\hline IL-2 receptor, U/mL & $223-710$ & 541 (331 to 837) & 1180 (931 to 1654$)$ & 0.001 \\
\hline IL-6, pg/mL & $<7.00$ & 22.20 (5.87 to 43.03$)$ & 55.77 (26.99 to 137.90$)$ & 0.016 \\
\hline IL-8, pg/mL & $<62.0$ & 21.9 (13.3 to 193.0$)$ & 27.2 (15.9 to 53.0$)$ & 0.945 \\
\hline $\mathrm{TNF} \alpha, \mathrm{pg} / \mathrm{mL}$ & $<8.1$ & 7.3 (5.9 to 11.8$)$ & $12.8(8.0$ to 19.6$)$ & 0.022 \\
\hline NT-proBNP, pg/mL & $<285$ & 46 (31 to 267$)$ & 970 (323 to 2535$)$ & $<0.001$ \\
\hline Cardiac troponin I, pg/mL & $\leq 15.60$ & 1.9 (1.9 to 5.0$)$ & 43.1 (11.0 to 239.4$)$ & $<0.001$ \\
\hline
\end{tabular}

${ }^{*} P$ values indicate differences between survivors and non-survivors. A value of $p<0.05$ was considered statistically significant. APTT, activated partial thromboplastin time; ESR, erythrocyte sedimentation rate; FEU, fibrinogen equivalent units; hsCRP, high-sensitivity C-reaction protein; IL, interleukin; NT-proBNP, N-terminal pro-brain natriuretic peptide; TNF $\alpha$, tumor necrosis factor $\alpha$.

diabetes in the outcome of patients with severe covid-19. We mainly illustrated that patients with severe covid-19 with diabetes were older, and had severer inflammation response compared with patients with severe covid-19 without diabetes. Furthermore, the Kaplan-Meier survival curve showed that the survival rate of patients with severe covid-19 with diabetes was significantly lower.
Previous studies suggested that patients with severe covid-19 had a high prevalence of diabetes, ${ }^{8914}$ which was nearly $20 \%$ compared with $11.6 \%{ }^{15}$ in Chinese adults. But few researches focused on the clinical characteristics of patients with severe covid-19 with diabetes and the direct correlation between diabetes and survival rate in patients with severe covid-19. Our observations 
were in line with previous findings that the prevalence of diabetes in patients with severe covid-19 is up to $24 \%$. Patients with diabetes were more likely to develop covid-19, which may be due to the fact that patients with diabetes had low pulmonary function. ${ }^{13}$ But the mechanisms explaining lung dysfunction in diabetes remain vague. Animal studies suggested that alveolar capillary microangiopathy and interstitial fibrosis were induced by glycosylation of the lung tissue collagen in the diabetes model, and this process was mediated by nicotinamide adenine dinucleotide phosphate (NADPH) oxidase and angiotensin II. ${ }^{16}{ }^{17}$ Autopsy also identified that patients with diabetes had thickening lung basal lamina, ${ }^{18}$ which may have an influence on pulmonary diffusion function.

According to our study, patients with severe covid-19 with diabetes had a similar pattern of clinical characteristics to patients with severe covid-19 without diabetes. Patients with severe covid-19 with diabetes had a high proportion of symptoms of cough and dyspnea, but it did not reach a statistically significant difference due to the small sample size.

The obvious laboratory abnormalities observed in our study were increased leukocytes, neutrophils and decreased lymphocytes in patients with severe covid-19 with diabetes compared with patients with severe covid-19 without diabetes. This observation may suggest that patients with diabetes had more serious infection of virus, and probably were inclined to accompany bacterial infection. In addition, inflammatory indicators were more severe in patients with severe covid-19 with diabetes, such as hsCRP, procalcitonin, IL-2 receptor, IL-6, IL-8 and TNFo. Several potential pathway studies suggested diabetes and obesity may lead to activate differentiation of CD4+ T cells though Th1 cell and Th2 cell, ${ }^{12} 1920$ and induce dysfunction of Th17 cells ${ }^{21}$ and Treg cells which affected the balance of proinflammation and anti-inflammation. ${ }^{22}$ And immune system imbalance may induce secretion of inflammatory cytokines. Additionally, increased level of urea nitrogen, albumin and NT-proBNP were also observed in our study. These abnormalities suggest that covid-19 infection may be associated with progressive systemic injury in patients with diabetes.

Diabetes was reported to increase the risk of complications in severe acute respiratory syndrome (SARS), H1N1 influenza virus infection and Middle East respiratory syndrome (MERS) ${ }^{23-26}$ Covid-19 was defined as $\beta$-coronavirus, which had $85 \%$ sequence similarity with SARS and $50 \%$ sequence similarity with MERS. ${ }^{27}$ The structural protein S of covid-19 invades lung cells though the binding of structural protein $\mathrm{S}$ to the receptors, such as ACE2 and CD147. ${ }^{28}$ Severe pneumonia causes lung damage, which may cause acute respiratory distress syndrome, and even lead to septic shock. Similar to previous studies, patients with severe covid-19 with diabetes in our study were particularly susceptible to receive mechanical ventilation and intensive care, and had higher mortality than those without diabetes. Meanwhile the median survival duration from hospital admission was significantly shortened in patients with diabetes compared with patients without diabetes. The mechanisms linking diabetes with higher mortality and shorter survival time in patients with diabetes were lung dysfunction and aggravated inflammation, which we discussed in the previous part. Another potential mechanism was that hyperglycemia was a risk factor for mortality. ${ }^{25}$ Hyperglycemia induced by diabetes was linked to aggressive glycosylation, ${ }^{29}$ which leads to overproduction of advanced glycation end products. And aberrant glycosylation was considered to be related to dysfunction of immunoglobulins. ${ }^{30}$ Dysregulation in glycosylation of IgG Fc domains may lead to susceptibility to infectious diseases. ${ }^{31}$ In addition, dysfunction of IgG may impair clearance function between phagocytic cell antigens (such as bacteria or virus, which may aggravate serious infection). And hyperglycemia may be due to following reasons: (1) Patients with severe covid-19 were unable to take food regularly, and the nutritional support was mainly though intravenous fluid infusion. (2) Covid-19 could cause dysfunction of gastrointestinal absorption. (3) Steroid treatment. (4) Infection itself can cause blood glucose fluctuation. Covid-19 was reported to use ACE2 as a receptor, ${ }^{27}$ which was expressed in lung, pancreas and other tissues. Covid-19 may bind to ACE2 in pancreas, which can damage pancreatic function and lead to hyperglycemia.

Among patients with severe covid-19 with diabetes, our observations were in line with previous findings that more non-survivors were men. ${ }^{7}$ The specific mechanism for covid-19 susceptibility in men was that expression of ACE2 in men was nearly three times more than women. ${ }^{32}$ In addition, non-survivors had severe inflammatory response, and cardiac, hepatic, renal and coagulation impairment, which is consistent with previous studies. $^{78}$

The strengths of the study are discussed as follows. First, our study found that diabetes was associated with high mortality and short survival duration in patients with severe covid-19. Second, clinical data of patients with severe covid-19 were collected from Tongji Hospital, which is a designated hospital responsible for the treatment of patients with severe covid-19 in Wuhan. Third, all authors are first line doctors, who could directly observe participants. There are several limitations of our study. First, the sample size was relatively small. Second, a retrospective method was used in our study. Third, high mortality was observed in our study. It may be explained by the fact that Tongji Hospital is the designated hospital for severe cases. In fact, with the accumulation of treatment experience, the mortality in patients with severe covid-19 dramatically decreases. So the real mortality in patients with severe covid-19 still needs further study on large sample.

In summary, our findings demonstrated that patients with severe covid-19 with diabetes were more likely to receive mechanical ventilation and admission to ICU, and had higher mortality. Patients with severe covid-19 
with diabetes exhibit severe inflammation response. Furthermore, our results suggest that diabetes can be considered a risk factor for death in patients with severe covid-19. Finally, intensive treatment for diabetes should be considered in the management of covid-19.

Acknowledgements The authors thank the participants for their willingness to participate in this study The authors also thank the staff who carried out the extensive clinical and nursing work in Tongji Hospital.

Contributors Author Contributions: KD, YoY, XY and YaY conceived the research and participated in the study design. YoY, FW, HR, SZ and XS assisted in collecting the data. YoY, FW and KD analyzed the data. KD and YoY drafted the manuscript. All authors read and approved the final manuscript.

Funding This work was supported by the National Natural Science Foundation of China (81600661).

Competing interests None declared.

Patient consent for publication Not required.

Ethics approval This study design and protocol were approved by the Ethics Committee of the Tongji Hospital of Tongji Medical College, Huazhong University of Science and Technology (ID: TJ-IRB20200315).

Provenance and peer review Not commissioned; externally peer reviewed.

Data availlability statement Data are available upon reasonable request.

Open access This is an open access article distributed in accordance with the Creative Commons Attribution Non Commercial (CC BY-NC 4.0) license, which permits others to distribute, remix, adapt, build upon this work non-commercially, and license their derivative works on different terms, provided the original work is properly cited, appropriate credit is given, any changes made indicated, and the use is non-commercial. See: http://creativecommons.org/licenses/by-nc/4.0/.

ORCID iDs

Yan Yang http://orcid.org/0000-0001-8146-8040

Xuefeng Yu http://orcid.org/0000-0003-3961-9321

Kun Dong http://orcid.org/0000-0003-3204-078X

\section{REFERENCES}

1 Chen N, Zhou M, Dong X, et al. Epidemiological and clinical characteristics of 99 cases of 2019 novel coronavirus pneumonia in Wuhan, China: a descriptive study. Lancet 2020;395:507-13.

2 Holshue ML, DeBolt C, Lindquist S, et al. First case of 2019 novel coronavirus in the United States. N Engl J Med 2020;382:929-36.

3 Rothe C, Schunk M, Sothmann P, et al. Transmission of 2019-nCoV infection from an asymptomatic contact in Germany. N Engl J Med 2020;382:970-1.

4 Young BE, Ong SWX, Kalimuddin S, et al. Epidemiologic features and clinical course of patients infected with SARS-CoV-2 in Singapore. JAMA 2020. doi:10.1001/jama.2020.3204. [Epub ahead of print: 03 Mar 2020].

5 Chan JF-W, Yuan S, Kok K-H, et al. A familial cluster of pneumonia associated with the 2019 novel coronavirus indicating personto-person transmission: a study of a family cluster. Lancet 2020;395:514-23.

6 Li Q, Guan X, Wu P, et al. Early transmission dynamics in Wuhan, China, of novel Coronavirus-Infected pneumonia. N Engl J Med Overseas Ed 2020;382:1199-207.

7 Yang X, Yu Y, Xu J, et al. Clinical course and outcomes of critically ill patients with SARS-CoV-2 pneumonia in Wuhan, China: a singlecentered, retrospective, observational study. Lancet Respir Med 2020. doi:10.1016/S2213-2600(20)30079-5. [Epub ahead of print: 24 Feb 2020]

8 Wang D, Hu B, Hu C, et al. Clinical characteristics of 138 hospitalized patients with 2019 novel coronavirus-infected pneumonia in Wuhan, China. JAMA 2020. doi:10.1001/ jama.2020.1585. [Epub ahead of print: 07 Feb 2020].

9 W-j G, Z-y N, Hu Y, et al. Clinical characteristics of coronavirus disease 2019 in China. N Engl J Med 2020.

10 Ouchi N, Parker JL, Lugus JJ, et al. Adipokines in inflammation and metabolic disease. Nat Rev Immunol 2011;11:85-97.

11 Mathis D. Immunological goings-on in visceral adipose tissue. Cell Metab 2013;17:851-9.

12 Xia C, Rao X, Zhong J. Role of T lymphocytes in type 2 diabetes and diabetes-associated inflammation. J Diabetes Res 2017;2017:1-6.

13 Klein OL, Aviles-Santa L, Cai J, et al. Hispanics/Latinos with type 2 diabetes have functional and symptomatic pulmonary impairment Mirroring kidney microangiopathy: findings from the Hispanic community health Study/Study of Latinos (HCHS/SOL). Diabetes Care 2016;39:2051-7.

14 Huang C, Wang Y, Li X, et al. Clinical features of patients infected with 2019 novel coronavirus in Wuhan, China. Lancet 2020;395:497-506.

$15 \mathrm{Xu} \mathrm{Y}$, Wang L, $\mathrm{He} \mathrm{J}$, et al. Prevalence and control of diabetes in Chinese adults. JAMA 2013;310:948-59.

16 Yang J, Tan Y, Zhao F, et al. Angiotensin II plays a critical role in diabetic pulmonary fibrosis most likely via activation of NADPH oxidase-mediated nitrosative damage. Am J Physiol Endocrinol Metab 2011;301:E132-44.

17 Popov D, Simionescu M. Alterations of lung structure in experimental diabetes, and diabetes associated with hyperlipidaemia in hamsters. Eur Respir J 1997;10:1850-8.

18 Weynand B, Jonckheere A, Frans A, et al. Diabetes mellitus induces a thickening of the pulmonary basal lamina. Respiration 1999;66:14-19.

19 Shirakawa K, Yan X, Shinmura K, et al. Obesity accelerates T cell senescence in murine visceral adipose tissue. J Clin Invest 2016;126:4626-39.

20 Deng T, Lyon CJ, Minze LJ, et al. Class II major histocompatibility complex plays an essential role in obesity-induced adipose inflammation. Cell Metab 2013;17:411-22.

21 Zhang C, Xiao C, Wang P, et al. The alteration of Th1/Th2/Th17/Treg paradigm in patients with type 2 diabetes mellitus: relationship with diabetic nephropathy. Hum Immunol 2014;75:289-96.

22 Jagannathan-Bogdan M, McDonnell ME, Shin H, et al. Elevated proinflammatory cytokine production by a skewed T cell compartment requires monocytes and promotes inflammation in type 2 diabetes. J Immunol 2011;186:1162-72.

23 Allard R, Leclerc P, Tremblay C, et al. Diabetes and the severity of pandemic influenza A (H1N1) infection. Diabetes Care 2010;33:1491-3.

24 Booth CM, Matukas LM, Tomlinson GA, et al. Clinical features and short-term outcomes of 144 patients with SARS in the greater Toronto area. JAMA 2003;289:2801-9.

25 Yang JK, Feng Y, Yuan MY, et al. Plasma glucose levels and diabetes are independent predictors for mortality and morbidity in patients with SARS. Diabet Med 2006;23:623-8.

26 Nassar MS, Bakhrebah MA, Meo SA, et al. Middle East respiratory syndrome coronavirus (MERS-CoV) infection: epidemiology, pathogenesis and clinical characteristics. Eur Rev Med Pharmacol Sci 2018:22:4956-61.

27 Lu R, Zhao X, Li J, et al. Genomic characterisation and epidemiology of 2019 novel coronavirus: implications for virus origins and receptor binding. Lancet 2020;395:565-74.

28 Wang K, Chen W, Zhou Y-S. SARS-CoV-2 invades host cells via a novel route: CD147-spike protein, 2020.

29 Erickson JR, Pereira L, Wang L, et al. Diabetic hyperglycaemia activates CaMKII and arrhythmias by O-linked glycosylation. Nature 2013;502:372-6.

30 Arnold JN, Wormald MR, Sim RB, et al. The impact of glycosylation on the biological function and structure of human immunoglobulins. Annu Rev Immunol 2007;25:21-50.

31 Wang TT. Igg Fc glycosylation in human immunity. Curr Top Microbiol Immunol 2019;423:63-75.

32 Wu C, Zheng S, Chen Y. Single-Cell RNA expression profiling of ACE2, the putative receptor of Wuhan 2019-nCoV, in the nasal tissue, 2020. 